\title{
HIF1-alpha expressing cells induce a hypoxic-like response in neighbouring cancer cells
}

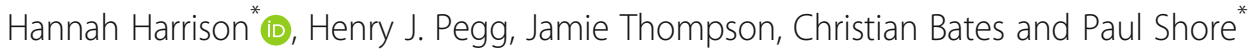

\begin{abstract}
Background: Hypoxia stimulates metastasis in cancer and is linked to poor patient prognosis. In tumours, oxygen levels vary and hypoxic regions exist within a generally well-oxygenated tumour. However, whilst the heterogeneous environment is known to contribute to metastatic progression, little is known about the mechanism by which heterogeneic hypoxia contributes to cancer progression. This is largely because existing experimental models do not recapitulate the heterogeneous nature of hypoxia.

The primary effector of the hypoxic response is the transcription factor Hypoxia inducible factor 1-alpha (HIF1-alpha). HIF1-alpha is stabilised in response to low oxygen levels in the cellular environment and its expression is seen in hypoxic regions throughout the tumour.

Methods: We have developed a model system in which HIF1-alpha can be induced within a sub-population of cancer cells, thus enabling us to mimic the effects of heterogeneic HIF1-alpha expression.

Results: We show that induction of HIF1-alpha not only recapitulates elements of the hypoxic response in the induced cells but also results in significant changes in proliferation, gene expression and mammosphere formation within the HIF1-alpha negative population.

Conclusions: These findings suggest that the HIF1-alpha expressing cells found within hypoxic regions are likely to contribute to the subsequent progression of a tumour by modifying the behaviour of cells in the non-hypoxic regions of the local micro-environment.
\end{abstract}

Keywords: Breast cancer, HIF-alpha, Hypoxia, Tumour micro-environment, Co-culture

\section{Background}

Tumour hypoxia greatly influences breast cancer progression [1-3] and is generally linked to poor prognosis in breast cancer patients due to increased proliferation, cell survival, invasive/metastatic ability, therapy-resistance and altered cancer stem cell activity [4-9]. The main mediator of signalling in these poorly oxygenated areas is Hypoxia inducible factor 1-alpha (HIF1-alpha) which is stabilised at low oxygen levels activating numerous downstream pathways [10].

Areas of hypoxia form as tumours outgrow their blood supply and exist within otherwise well-oxygenated

\footnotetext{
* Correspondence: hannah.harrison@manchester.ac.uk; paul.shore@manchester.ac.uk; http://paulshorelab.org/ Faculty of Biology, Medicine and Health, University of Manchester, Michael Smith Building, Oxford Road, Manchester M13 9PT, UK
}

tumours. The hypoxic landscape is very dynamic and oxygen levels fluctuate and hypoxic areas shift as the tumour progresses and new blood supplies are formed [11]. How the hypoxic tumour micro-environment contributes to cancer progression and metastasis is not fully understood and this is in part due to a lack of experimental models in which the heterogeneous nature of hypoxia can be modelled. Currently, in vitro, hypoxia is modelled in hypoxic incubators set at low oxygen levels (e.g. 1\%) [6] or by treating cells with a chemical mimetic, such as Dimethyloxalylglycine (DMOG) or cobalt chloride $\left(\mathrm{CoCl}_{2}\right)$ [12]. These methods expose the whole population of cells to hypoxia, which is a situation that is unlikely to exist in tumours.

We have therefore developed a novel model in which heterogeneous expression of HIF1-alpha can be induced

(c) The Author(s). 2018 Open Access This article is distributed under the terms of the Creative Commons Attribution 4.0 International License (http://creativecommons.org/licenses/by/4.0/), which permits unrestricted use, distribution, and reproduction in any medium, provided you give appropriate credit to the original author(s) and the source, provide a link to the Creative Commons license, and indicate if changes were made. The Creative Commons Public Domain Dedication waiver (http://creativecommons.org/publicdomain/zero/1.0/) applies to the data made available in this article, unless otherwise stated. 
in a sub-population of cells. Uniquely, this model enables analysis of changes in HIF1-alpha expressing cells and their effect on surrounding cells in which HIF1-alpha is not expressed. Using this model we demonstrate that, in addition to changes in proliferation, gene expression and mammosphere forming cell activity in the HIF1-alpha expressing cells, significant changes also occur within the HIF1-alpha negative population. These findings demonstrate that HIF1-alpha expressing cancer cells have a profound effect on the co-cultured HIF1-alpha negative cells. Similar effects are likely to be seen in tumours with hypoxic, HIF1-alpha positive cells having influence upon the normoxic cells surrounding them. These changes to the local micro-environment may be important in disease progression and metastasis.

\section{Methods}

\section{Cell lines}

MCF7 and MDA-MB-231 were purchased from American Type Culture Collection (ATCC ${ }^{\circ} \mathrm{HTB}^{2} 2^{\text {tw }}$ and HTB-26 $\left.6^{\mathrm{Tm}}\right)$. Cell lines were established for use in cell culture and no ethical approval was required for their use. Lines were authenticated by multiplex-PCR assay using the AmpF/STR system (Applied Biosystems) and confirmed as mycoplasma free. Monolayers were grown in complete medium (DMEM/10\% FCS/2 mmol/ L L-glutamine/PenStrep) and maintained in a humidified incubator at $37{ }^{\circ} \mathrm{C}$ at an atmospheric pressure of $5 \%(\mathrm{v} / \mathrm{v})$ $\mathrm{CO}_{2}$ /air.

\section{Inducible cell line production}

A yellow fluorescent protein tagged destabilising domain YFP-DD was removed from pBMN YFP-DHFR (DD) (a gift from Thomas Wandless, Addgene plasmid \# 29326) and cloned into HA-HIF1-alpha P402A/P564A-pcDNA3 (a gift from William Kaelin, Addgene plasmid \# 18955). The new vector, mHIF-YFP-DD-pcDNA3 was used to transfect MCF7 and MDA-MB-231 using Lipofectamine 2000 according to manufacturer's instructions. Following selection with G418 cells were FACS sorted as single cells to produce stable, clonal cell lines. Proteins fused with YFP-DD are made unstable and although they are transcribed and translated continually, they are not seen to be expressed. Trimethoprim (TMP, Cay-16,473, Cayman) was used to induce stabilisation of the fusion.

\section{Hypoxic and hypoxia mimetic cell culture}

Cells we incubated for $48 \mathrm{~h}$ in the SCI-tiveN hypoxic workstation (Ruskinn) in $1 \% \mathrm{O}_{2}, 5 \% \mathrm{CO}_{2}$ and $94 \% \mathrm{~N}_{2}$ in a humidified environment at $37{ }^{\circ} \mathrm{C}$. Cells were plated, cultured, and harvested within the workstation to maintain hypoxia at all times. For cobalt chloride $\left(\mathrm{CoCl}_{2}\right)$ induction, $100 \mu \mathrm{M} \mathrm{CoCl}{ }_{2}$ was added to fresh culture medium and cells were incubated for $48 \mathrm{~h}$ in a humidified incubator at $37{ }^{\circ} \mathrm{C}$ at an atmospheric pressure of $5 \%(\mathrm{v} / \mathrm{v}) \mathrm{CO}_{2} /$ air. Following hypoxic culture or exposure to $\mathrm{CoCl}_{2}$, induction of HIF1-alpha was verified by Western blot (Additional file 1: Figure S4).

\section{Conditioned medium}

Conditioned medium (CM) was collected and spun at $1000 \mathrm{~g}$ for $10 \mathrm{~min}$ to remove cell debris. CM was stored at $-20{ }^{\circ} \mathrm{C}$ for no longer than 2 weeks. $\mathrm{CM}$ was mixed 50:50 for fresh complete medium before being used to treat cells. The HIF1 inhibitor YC-1 was added to monolayer culture at a concentration of $10 \mathrm{mmol} / \mathrm{L}$ YC-1 (Cayman Chemicals).

\section{Mammosphere culture}

Mammosphere culture was carried out as previously described [13], and spheres greater than $50 \mu \mathrm{m}$ were counted on day 5. Briefly, cells were plated in non-adherent culture as single cell suspensions at a concentration of 2500 cells/ 6 well plate. Cells were cultured in DMEM:F12 supplemented with B27 (Thermo Fisher) for 5 days.

\section{Co-culture}

Parental and inducible cells were mixed at a ratio of 50:50 and cultured in the presence of TMP for $48 \mathrm{~h}$. Cells were then separated based upon expression of YFP using the FACS Aria. When comparing to mono-culture all cells were passed through the sorter to account for any pressure/sorting effect.

\section{Proliferation assay}

Cells were plated on glass cover slides for $24 \mathrm{~h}$. ClickIT ${ }^{\mathrm{Tm}}$ EdU kit Plus EdU Alexa Fluor ${ }^{\text {Th }} 647$ Imaging Kit (C10640, Thermo) was used according to manufacturer's instructions. Briefly cells were cultured with EdU for $45 \mathrm{~min}$ to allow incorporation of fluorescently labelled EdU into newly synthesized DNA therefore marking the proliferating cells. Cells were then fixed, permeablised and labelled with ClickIT-647.

\section{Nuclear/cytoplasmic separation}

Cells were resuspended in $400 \mu \mathrm{l}$ of ice cold Buffer A (10 mM HEPES pH 7.9, $10 \mathrm{mM} \mathrm{KCl,} 0.1 \mathrm{mM}$ EDTA, $0.1 \mathrm{mM}$ EGTA, $1 \mathrm{mM}$ DTT, $0.5 \mathrm{mM}$ PMSF) with the addition of complete mini-EDTA-free protease inhibitor cocktail (Roche) and incubated at $4{ }^{\circ} \mathrm{C}$ for $15 \mathrm{~min}$. Cells were lysed with $10 \%$ NP-40 (Sigma) before centrifuging at $4{ }^{\circ} \mathrm{C}$ and removal of the cytoplasmic extracts in the supernatant. The pellet was then resuspended in ice cold Buffer B (20 mM HEPES pH 7.9, 0.4 M NaCl, $1 \mathrm{mM}$ EDTA, $1 \mathrm{mM}$ EGTA, $1 \mathrm{mM}$ DTT and $1 \mathrm{mM}$ PMSF) containing protease inhibitors and vortexed vigorously for $45 \mathrm{~min}$ at $4{ }^{\circ} \mathrm{C}$. Nuclear proteins were collected from 
supernatant following centrifugation at $4{ }^{\circ} \mathrm{C}$. Both the nuclear and cytoplasmic extracts were stored at $-80{ }^{\circ} \mathrm{C}$ for future use.

\section{Immunocytochemistry}

Cells were grown in monolayer on coverslips for $48 \mathrm{~h}$ +/- $10 \mu \mathrm{M}$ Trimethoprim (TMP). Medium was removed and cells were fixed and permeablised with $4 \%$ formaldehyde and $0.1 \%$ Triton for $20 \mathrm{~min}$ at room temperature. Non-specific binding was blocked using 1\% BSA before antibody staining: rabbit anti-GFP (ab290, Abcam), Phalloidin-TRITC (P1951, SIGMA) or Phalloidin-iFluor 647 (ab176759, Abcam), Goat anti-Rabbit Alexa Fluor 488 (A11008, Thermo) and Goat anti-Mouse Cyanine3 (A10521, Thermo). Coverslips were mounted with ProLong $^{\text {Tx }}$ Gold Antifade Mountant with DAPI (P36940, Thermo).

\section{Image analysis}

Images were collected on a Zeiss Axioimager.D2 upright microscope using a $10 \times$ objective and captured using a Coolsnap HQ2 camera (Photometrics) through Micromanager software v1.4.23. Specific band pass filter sets for DAPI, FITC and Cy5 were used to prevent bleed through from one channel to the next. Images were then processed and analysed using Fiji ImageJ (http://imagej.net/Fiji/Downloads) [14] which is freely available online.

\section{Western blotting}

Protein was separated on an SDS-PAGE and transferred to Hybond-C Extra nitrocellulose membrane. Primary antibodies included: HIF-1a (610,959, BD Biosciences) and Lamin B1 (ab16048, Abcam).

Densitometry was conducted using ImageJ software, which is freely available at http://rsb.info.nih.gov/ij/.

\section{Quantitative reverse transcription PCR}

RNA was extracted using the Qiagen RNAeasy kit according to manufacturer's instructions and quantified on the Nanodrop spectrophotometer (Thermo). Real time one step qRT-PCR was carried out using the QuantiTect SYBR $^{\bullet}$ Green RT-PCR Kit (Qiagen) according to manufacturer's instructions before analysis on the 7900 PCR machine (Applied Biosystems).

\section{Statistical analysis}

Data is represented as mean +/- SEM. Statistical significance was measured using parametric testing, assuming equal variance, in the majority of experiments with standard $\mathrm{t}$ tests for 2 paired samples used to assess difference between test and control samples.

\section{Results}

Inducible HIF1-alpha cancer cell lines

To determine the effects of HIF1-alpha expressing cells on the surrounding HIF1-alpha negative cells we developed a model culture system in which HIF1-alpha can be induced in a sub-population of cells. To achieve this we fused a YFP-tagged destabilising domain (YFP-DD) to HIF1-alpha, thus enabling the stabilising effect of hypoxia on HIF1-alpha to be mimicked by the addition of an inducer molecule $[15,16]$. The DD fusion protein is stable in the presence of Trimethoprim (TMP) but when TMP is removed the protein rapidly degrades (Fig. 1a). In this model YFP-DD was fused to a mutant form of HIF1-alpha (mHIF) which is stable in normoxia [17]. This fusion was stably expressed in MCF7 (ER+) and MDA-MB-231 (ER-) breast cancer cell lines [MCF7-mHIF-YFP-DD and 231-mHIF-YFP-DD] and inducible expression was verified by Western blot for HIF1-alpha performed on nuclear extracts following $48 \mathrm{~h}$ of culture with $10 \mu \mathrm{M}$ TMP (Fig. 1b, Additional file 1: Figure S1 shows an unedited blot). Control lines were produced expressing YFP-DD only (MCF7-YFP-DD and 231-YFP-DD, data not shown).

To assess localisation and control of induction, MCF7-mHIF-YFP-DD and 231-mHIF-YFP-DD cells were cultured with $10 \mu \mathrm{M}$ TMP for $48 \mathrm{~h}$. Cells were then fixed and stained with an anti-GFP antibody to identify HIF1-alpha positive cells and Phalloidin-TRITC and DAPI to define the cytoplasm and nucleus respectively. Nuclear localisation, which is required for active HIF1-alpha signalling, was not affected by the increased size resulting from fusion to YFP-DD as the protein was present in the nucleus of induced cells (Fig. 1c). Activation of HIF1-alpha target genes was subsequently determined using qRT-PCR for three known genes. Significant increases in VEGF, EPO and CAIX were seen following the addition of $10 \mu \mathrm{M}$ TMP (Fig. 1d). No change was observed in the control lines.

Induction occurred quickly with a significant increase in expression after $1 \mathrm{~h}$ in MCF7 cells and $30 \mathrm{~min}$ in MDA-MB-231. Expression reached its highest level by $24 \mathrm{~h}$ in both lines (Fig. 1e). Following removal and wash out of TMP, expression rapidly decreased returning to un-induced levels after $8 \mathrm{~h}$. If TMP was not removed, induction remained high over 4 days following a single treatment with $10 \mu \mathrm{M}$ TMP (Fig. 1f). Taken together these data show that the stabilising effect of hypoxia on HIF1-alpha can be mimicked by the addition of TMP in these cell lines.

\section{Stabilising HIF1-alpha with TMP mimics known hypoxic responses}

We next determined if stabilising HIF1-alpha by the addition of TMP simulated the response known to be 

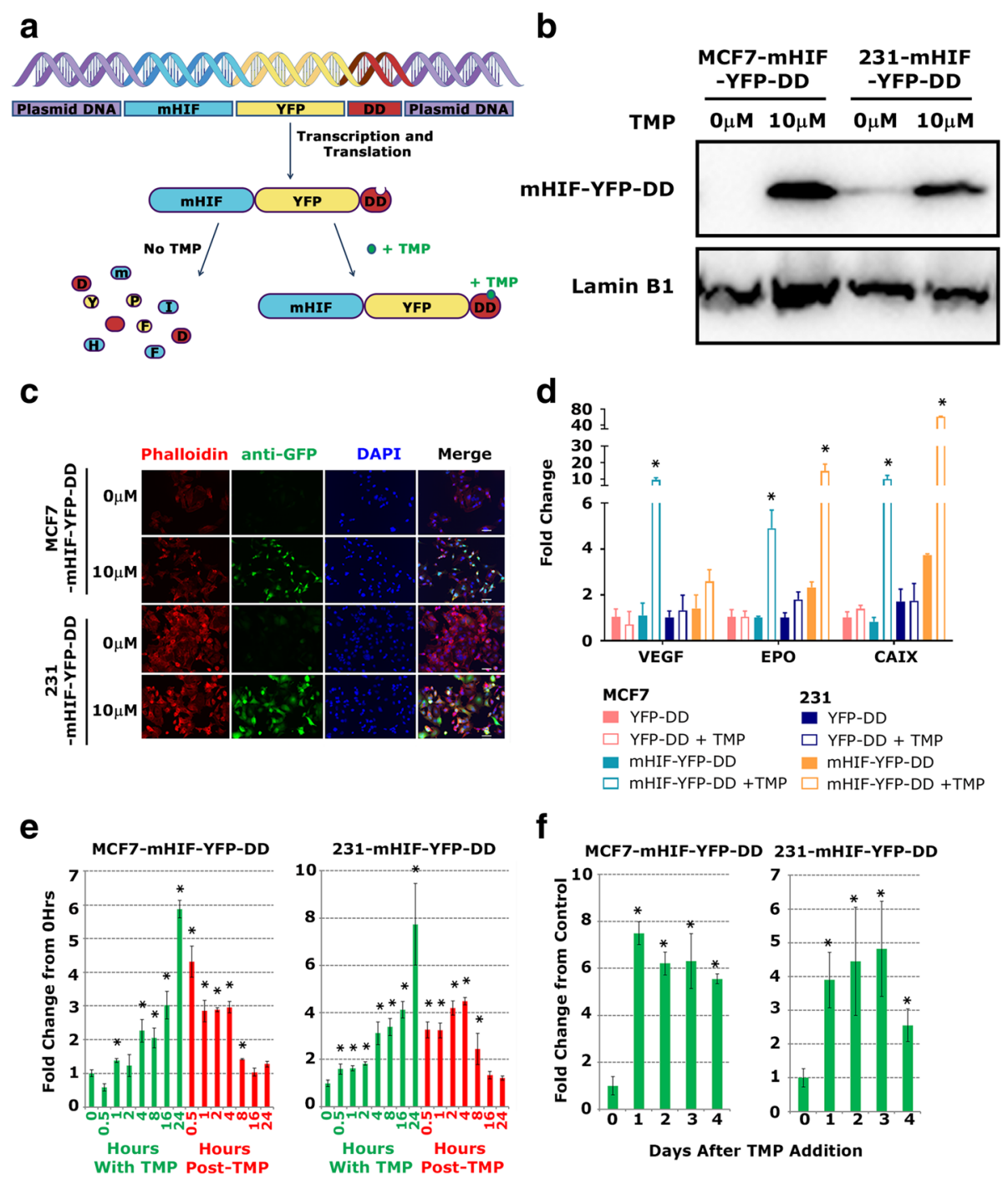

$\mathbf{f}$

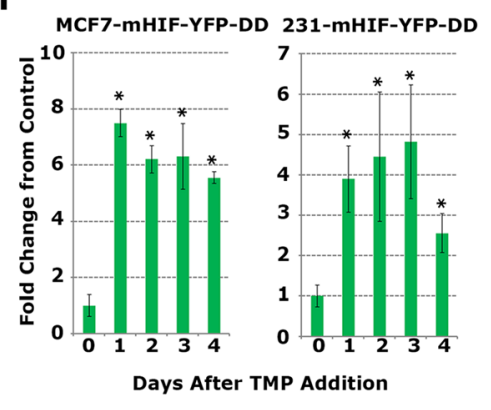

Fig. 1 a Schematic detailing the inducible system used in our novel cell line model. A mutant form of HIF1-alpha (mHIF) which is stable in normoxia is fused to a YFP-tagged destabilising domain. The fusion is readily transcribed and translated but is unstable and broken down in the absence of Trimethoprim (TMP). When TMP is added the fusion is stabilised and expressed. $\mathbf{b}$ Stabilisation and expression following addition of $10 \mu \mathrm{M}$ TMP was assessed by Western blot of nuclear extracts. Western blots were performed on single membranes cut in two with upper section labelled for mHIF and lower section labelled for Lamin B1. c To activate downstream signalling HIF1-alpha must interact with HIF1-beta to translocate into the nucleus. Successful nuclear translocation was verified by immunocytochemistry. Scale bar equal to $25 \mu \mathrm{m}$. $\mathbf{d}$ qRT-PCR was performed on control (YFP-DD) and inducible (mHIF-YFP-DD) cells in the presence or absence of $10 \mu \mathrm{M}$ TMP. Gene expression was seen to change in the inducible cells suggesting HIF1-alpha activation of signalling. e Expression of MHIF-YFP-DD was measured over time following addition of TMP (green bars) and following wash out of TMP (red bars) in both MCF7 and 231 lines. Significantly increased expression was seen in both lines within $1 \mathrm{~h}$ and the signal had returned to normal after $8 \mathrm{~h}$. f Expression of mHIF-YFP-DD was measured over time following addition of a single dose of TMP at Day 0. Expression remained elevated over 4 days

induced by hypoxia $\left(1 \% \mathrm{O}_{2}\right)$ and a chemical hypoxia mimetic $(100 \mu \mathrm{M} \mathrm{CoCl} 2)$. qRT-PCR was performed on a panel of known HIF1-alpha target genes (VEGF, GLUT1, EPO, CAIX and TGFA) after $48 \mathrm{~h}$ induction with TMP, hypoxia or $\mathrm{CoCl}_{2}$. In all three conditions target genes were induced to similar levels (Fig. 2a). TMP had no effect on gene expression (data not shown).

Hypoxic culture is known to have a contrasting effect on the cancer stem cell (CSC) population in breast cancer depending upon the disease sub-type [6]. In breast cancers which express estrogen receptor (ER), CSC activity increases following exposure to hypoxia. In contrast, there is a significant decrease in CSC activity in ER-negative tumours. This effect was previously shown to be directly down-stream of HIF1-alpha as siRNA targeting HIF1-alpha blocked the effect of hypoxic culture completely [6]. To assess whether the same effects were seen in our HIF1-alpha expressing cells, mammosphere formation was assessed following $48 \mathrm{~h}$ of culture with TMP. Mammosphere number was increased in 


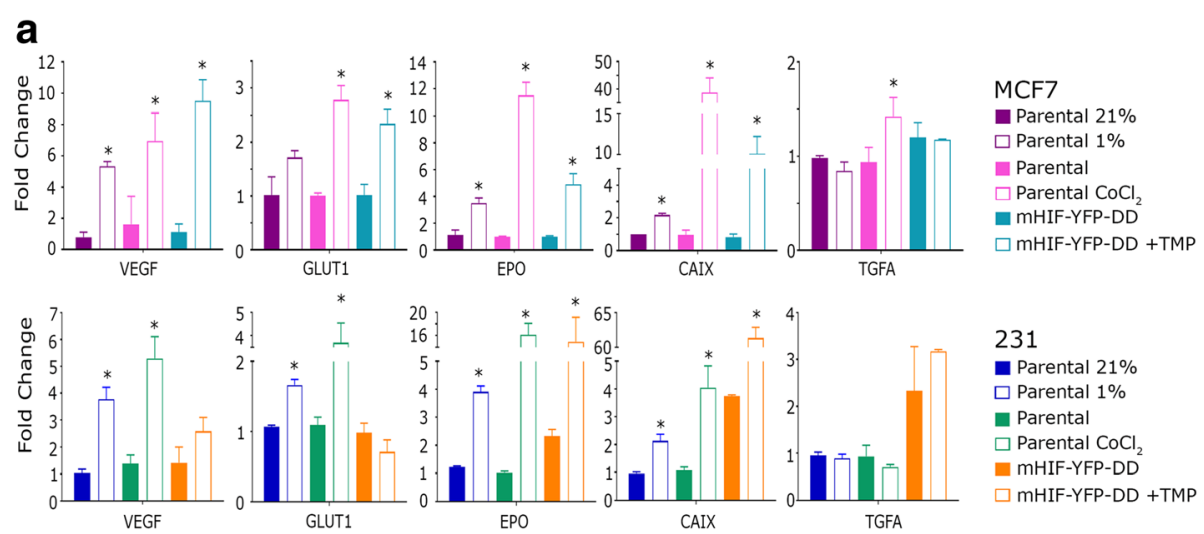

b
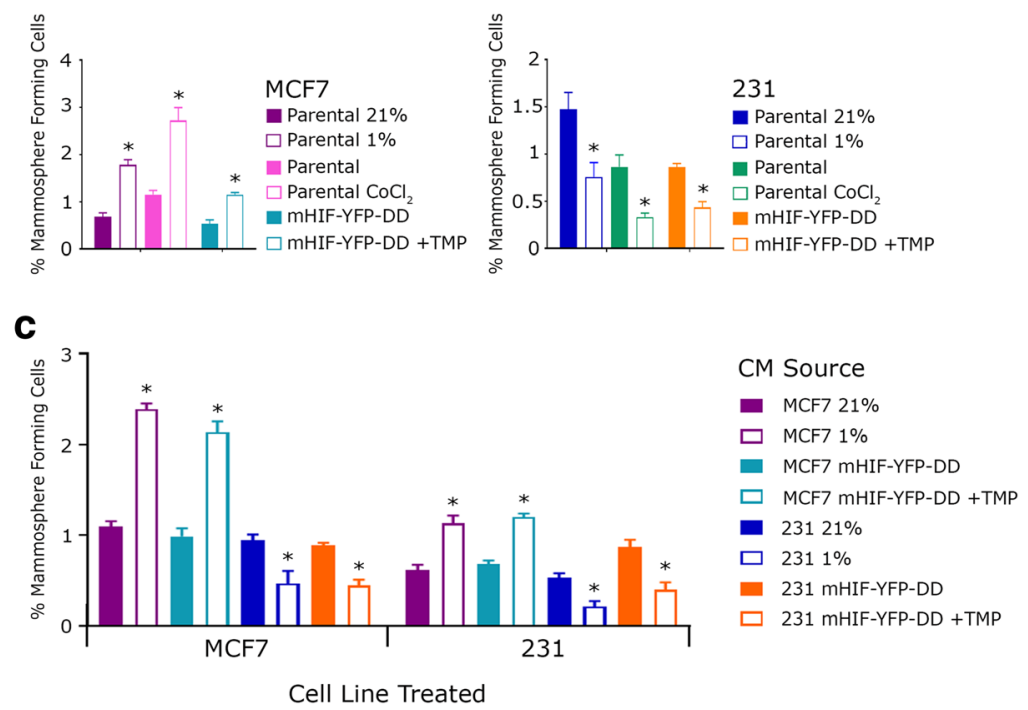

Fig. 2 a qRT-PCR was performed for cells from hypoxic culture (parental 21\% vs 1\% $\mathrm{O}_{2}$ ), hypoxia mimetic culture (parental $+/-\mathrm{CoCl}_{2}$ ) and our HIF1-alpha inducible system (mHIF-YFP-DD +/- TMP). A similar pattern was seen in all conditions. b Following $48 \mathrm{~h}$ in hypoxic culture (parental $21 \%$ vs $1 \% \mathrm{O}_{2}$ ), hypoxia mimetic culture (parental $+/-\mathrm{CoCl}_{2}$ ) or our HIF1-alpha inducible system (mHIF-YFP-DD $+/-$ TMP) cells were plated in mammosphere culture. A comparable response was seen in all conditions. c Conditioned medium was collected from cells cultured in hypoxia (parental $21 \%$ vs $1 \% \mathrm{O}_{2}$ ) or our HIF1-alpha inducible system (mHIF-YFP-DD +/- TMP) and was used to treat parental cells (MCF7 and MDA-MB231) for $48 \mathrm{~h}$. These cells were then plated in mammosphere culture. The conditioned medium induced the same hypoxic response as the culture condition from which it came regardless of the cells being treated

MCF7-mHIF-YFP-DD cells and decreased in 231-mHIFYFP-DD cells as is seen in hypoxic culture and following $\mathrm{CoCl}_{2}$ exposure (Fig. 2b).

Secreted factors are known to play a major role in the regulation of hypoxia in tumour signalling both locally and to distant sites [18]. We aimed, therefore, to assess whether the CSC response seen following hypoxic culture or following HIF1-alpha induction in our model was controlled via secreted signals. Conditioned medium (CM) taken from cells cultured in hypoxia had the same effect on mammosphere formation as hypoxic culture itself regardless of the cell type being treated; CM taken from MCF7 (ER+) cells caused an increase in mammosphere number in both MCF7 and MDA-MB-231 whilst CM taken from MDA-MB-231 (ER-) caused a decrease in mammosphere formation in both MDA-MB-231 and MCF7 cells (Fig. 2c). This effect was blocked with addition of the HIF1-alpha inhibitor YC-1 during production of CM (Additional file 1: Figure S2). The same paracrine effects were seen when using $\mathrm{CM}$ collected from inducible lines; $\mathrm{CM}$ collected from MCF7-mHIF-YFP-DD and 231-mHIF-YFP-DD treated with TMP resulted in altered mammosphere formation in both MCF7 and MDA-MB-231 (Fig. 2c). Our data suggest that the HIF1-alpha induced mammosphere response is mediated by paracrine signals secreted by the hypoxic or HIF1-alpha expressing cells. The secreted factor (s) is different depending on the cell type releasing it and its effect is not cell type specific as CM from either cell line induced the same response in both parental 
lines. This supports the hypothesis that the hypoxic cancer cells within a tumour can influence the local micro-environment by affecting the different cell types surrounding them.

\section{Expression of HIF1-alpha in a sub-population of cancer cells induces significant changes in surrounding cells}

To simulate the heterogeneous nature of HIF1-alpha expression that is seen within a population of tumour cells we generated co-cultures by mixing wild-type MCF7 or MDA-MB-231 cells with HIF1-alpha inducible cells. TMP was added to co-cultures for $48 \mathrm{~h}$ before cells were isolated by flow sorting to separate HIF1-alpha positive (YFP positive) from negative cells (Additional file 1: Figure S3). These cultures were subsequently used to examine the effects of the HIF1-alpha positive cells on the surrounding parental sub-population.

Following co-culture and separation, MCF7 and MDA-MB-231 cells were plated into non-adherent culture to assess the effects on mammosphere formation. Induction of HIF1-alpha in mono-culture resulted in increased and decreased mammosphere formation as expected in MCF7 and MDA-MB-231 respectively (Fig. 3a). Importantly we observed that TMP induction of HIF1-alpha in MCF7 co-cultures also resulted in a significant increase in mammosphere formation in the non-induced sub-population of cells (Fig. 3a). In MDA-MB-231 co-cultures a reduction in mammospheres was observed. Moreover, qRT-PCR analysis of the HIF1-alpha target genes also revealed a significant increase in their expression in the parental, co-cultured cells (Fig. 3b). This included an increase in TGF-alpha expression in the parental cell lines following co-culture, a change which is not seen in the HIF1-alpha positive inducible cells grown in either mono- or co-culture or in those cultured in hypoxia (1\%) or $\mathrm{CoCl}_{2}$ culture. All genes responded similarly to HIF1-alpha induction in the HIF1-alpha expressing cells in both mono- and co-cultures (Fig. 3b). To determine the effects of HIF1-alpha induction on the proliferative capacity of neighbouring cells, ClickIT Edu was used to assess changes in proliferation after HIF1-alpha induction in co-cultured cells. HIF1-alpha negative cell proliferation was altered in MCF7 and MDA-MB-231 when grown in co-culture with HIF1-alpha expressing cells; MCF7 cells proliferated more quickly whilst MDA-MB-231 cells grew more slowly (Fig. 3c). HIF1-alpha has been shown to reduce proliferation in cancer cells [19] and, as expected, the HIF1-alpha positive cells proliferated more slowly than the parental cells in monoculture of both lines. Interestingly, the HIF1-alpha expressing cells proliferated more quickly when grown in co-culture and in the case of MDA-MB-231 there was no significant difference between the parental and inducible cells in this case. This change suggests a bi-directional effect of co-culture on proliferation suggesting a great deal can be learned from this system.

Taken together, these data reveal that induction of HIF1-alpha expression in a sub-population of cancer cells has a significant effect on gene expression, the mammosphere forming population and the proliferative capacity of the surrounding cancer cells. Thus our model system has revealed a complex interplay between HIF1-alpha positive and negative cancer cells that are likely to have a significant effect on the development of a tumour.

\section{Discussion}

The inducible system described here allows HIF1-alpha, the main regulator of hypoxia, to be switched on and off within a sub-population of cells. In our model HIF1-alpha stabilises and degrades within a relatively short period of time and, although these kinetics may not exactly replicate those seen in vivo, this will allow us to model fluctuations in expression of the protein and enable us to gain a more realistic view of its effects on cancer cells within a tumour. All of the experiments were performed in normoxic conditions enabling the specific effects of HIF1-alpha induction to be determined in the absence of further confounding changes due to hypoxia.

Using a co-culture model we have demonstrated that expression of HIF1-alpha is sufficient to induce the same expression changes in important target genes as commonly observed in hypoxia and $\mathrm{CoCl}_{2}$ exposure. Also, the induction of HIF1-alpha causes the same contrasting effect on mammosphere forming cells in MCF7 and MDA-MB-231 cells that result from hypoxic and $\mathrm{CoCl}_{2}$ culture [6]. This model system revealed that when cultured together with parental cells, there is a significant effect on mammosphere formation in this HIF1-alpha negative population. Mammosphere formation increases in parental MCF7 and decreases in MDA-MB-231 when cultured in the vicinity of HIF1-alpha expressing cells. As MS are thought to be representative of the CSC population [13] this is potentially of great importance as it implies that the CSC population in tumours may be altered both within and outside of the hypoxic zones. This would mean that the effects of hypoxia could be far more wide reaching than initially assumed. Further verification of changes to the CSC population are required before any solid conclusions can be drawn. These HIF1-alpha induced changes in the parental cell population could not have been identified using hypoxic chambers and chemical mimetics.

Our model allows us to separate and investigate the effects of the main hypoxia regulator, HIF1-alpha, from 

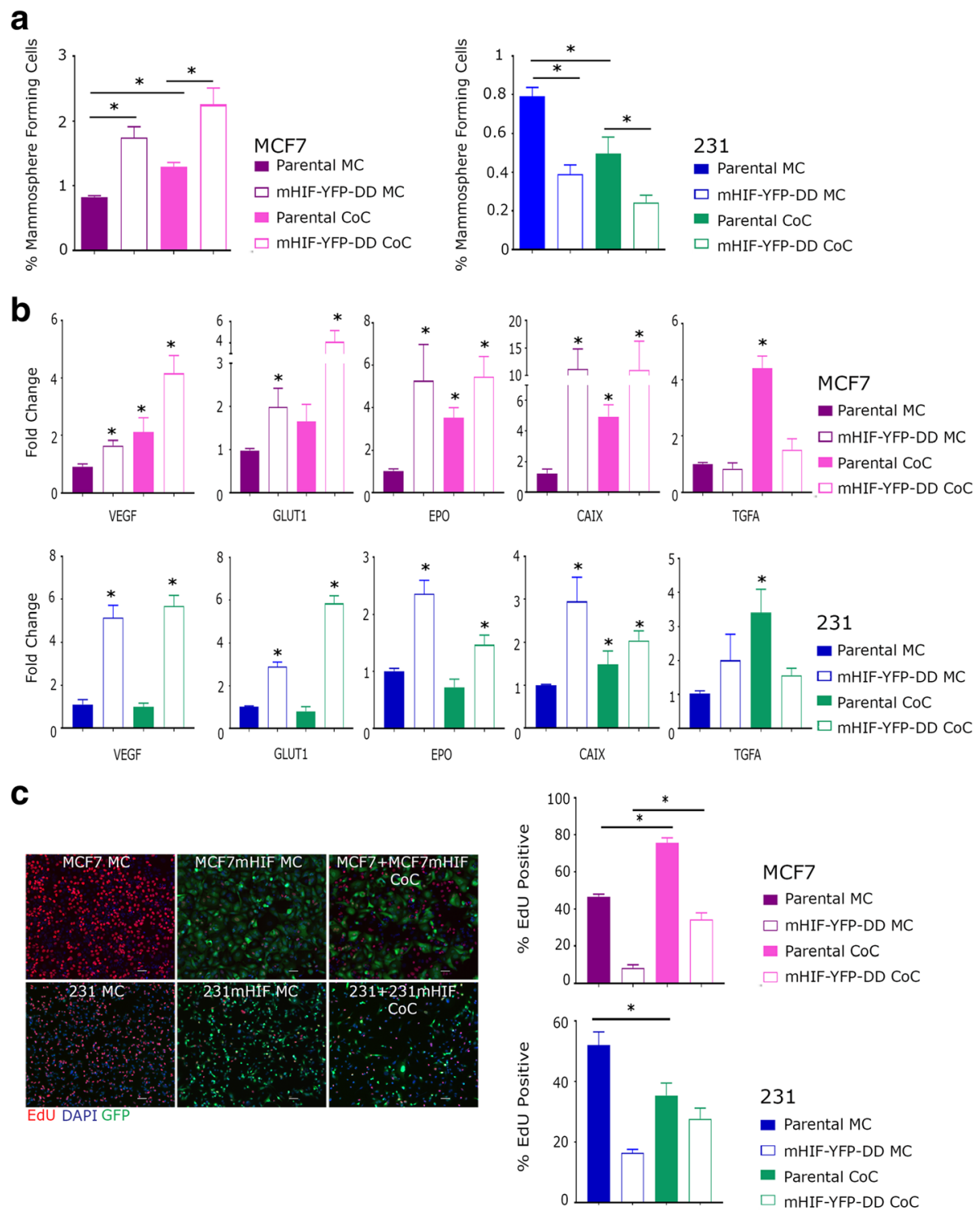

Fig. 3 Following $48 \mathrm{~h}$ in the presence of TMP in either mono-culture (MC) or co-culture (CoC), mHIF-YFP-DD and parental cells were plated into mammosphere culture or used to make RNA for qRT-PCR. a Mammosphere formation increased or decreased in the mHIF-YFP-DD expressing lines as expected in MCF7 and 231 cells respectively. Interestingly, mammosphere forming cell number was also affected in the both parental cell lines following co-culture. $\mathbf{b}$ Gene expression changes were seen within the HIF1-alpha inducible cells as expected. Changes were also visible, however, in the parental cells grown in co-culture. c Representative photomicrographs showing EdU stain in mono- and co-culture, Green anti-GFP, Blue DAPI and Red EdU. Scale bar equal to $25 \mu \mathrm{m}$. Proliferation, assessed by counting cells positive for EdU, was increased in mHIF-YFPDD and parental cells cultured in co-culture

other factors which are involved in the hypoxic response within tumours, expression of HIF2-alpha for example. This allows us to see more clearly the effects of HIF1-alpha and may allow us to further elucidate the role of this protein in the hypoxic and non-hypoxic zones of a tumour. Studying the effects of these other factors is of course important and work is underway to investigate them in our model system.

Co-culture of our inducible cells with the parental lines also showed gene expression changes within the parental HIF1-alpha-negative cells. Changes included an increase in TGF-alpha expression which was not seen in the HIF1-alpha positive inducible cells or in those cultured in hypoxia $(1 \%)$ or with $\mathrm{CoCl}_{2}$. TGF-alpha is a known target of HIF1-alpha [20] but it was not activated within our HIF1-alpha induced or hypoxic cultured cells. TGF-alpha has been previously suggested as a marker of poor outcome at follow-up and specifically for lymph node metastasis [21], whether this is linked to hypoxia is yet to be seen but this kind of change in the bulk of the 
tumour may explain how HIF1-alpha induction by hypoxia in the primary tumour can increase metastasis even though this recurrence often happens many years after removal of the primary tumour.

Proliferation rates were seen to be affected in both the parental and HIF1-alpha expressing cells during co-culture experiments. This bi-directional signalling cannot be identified using conventional culture systems. This data further suggests that reduced oxygen may affect not only the cells within the hypoxic region, which are expressing HIF1-alpha, but also the bulk of the tumour and supports the need for a culture system in which HIF1-alpha negative cells are represented alongside HIF1-alpha expressing cells as this change would not be seen in conventional culture.

This new inducible co-culture system allows HIF1-alpha induction within a sub-population of cancer cells and so facilitates the analysis of the complex interplay between HIF1-alpha positive and negative cells, which are found within hypoxic and normoxic tumour cells. We also note that stabilisation of HIF1-alpha is fast and the ligand can be washed out of the system with expression falling quickly. Thus the system also allows the effects of the dynamic changes in HIF1-alpha seen in tumour hypoxia to be analysed. This is important as it will allow us to model the fluctuating hypoxia observed in tumours [11]. Finally, co-culture with other cell types from the local micro-environment is also possible and this may reveal more complexity in the hypoxia induced response to HIF1-alpha in tumours.

\section{Conclusions}

This model offers the opportunity to study, in detail, the complex interactions between HIF1-alpha expressing cells and those around them. This may offer insight into the effects HIF1-alpha expressing cells have on their local micro-environment leading to altered metastasis and disease progression. Our data shows a clear bi-directional effect within the co-culture environment which could not be identified previously.

This unique model can easily be adapted to produce inducible co-cultures with other genes, which are important in other environments and diseases, meaning it offers a great deal of potential to the wider scientific community.

\section{Additional file}

Additional file 1: Figure S4. HIF activation by hypoxic and mimetic culture. A. Western blot was first labelled for HIF (Left), then washed and re-blotted for Tubulin (right). This unedited western shows MCF7 and MDA-MB-231 parental cells cultured in $21 \%$ and $1 \%$ oxygen for 48 hours before lysis. B. Western blot was cut at approximately $80 \mathrm{kDa}$ and the top was labelled for HIF1 whilst the bottom was labelled for Tubulin. This unedited western shows MCF7 and MDA-MB-231 parental cells exposed to varying concentrations of CoCl2. (PPTX $1037 \mathrm{~kb}$ ).

\section{Abbreviations}

BSA: Bovine serum albumin; CAIX: Carbonic anhydrase; $\mathrm{CoCl}_{2}$ : Cobalt chloride; CSC: Cancer stem cell; CY5: Cyanine 5; DAPI: 4',6-diamidino-2phenylindole; DD: Destabilising domain; DMEM: Dulbecco Modified Eagle Medium; DMOG: Dimethyloxallyl Glycine; EPO: Erythropoietin; ER: Oestrogen receptor; FACS: Fluorescence-activated cell sorting; FCS: Foetal calf serum; FITC: Fluorescein isothiocyanate; GFP: Green fluorescent protein;

GLUT1: Glucose transporter 1; HIF1: Hypoxia inducible factor 1; mHIF: Mutant hypoxia inducible factor; SDS-PAGE: Sodium dodecyl sulfate polyacrylamide gel electrophoresis; SEM: Standard error of mean; TGFA: Transforming growth factor alpha; TMP: Trimethoprim; TRITC: Tetramethylrhodamine;

VEGF: Vascular endothelial growth factor; YFP: Yellow fluorescent protein

\section{Acknowledgements}

The Bioimaging Facility microscopes used in this study were purchased with grants from BBSRC, Wellcome and the University of Manchester Strategic

Fund. Special thanks go to Roger Meadows and Steven Marsden for their help with the microscopy.

The FACS Aria within the flow cytometry core was purchased with funding from the MRC. Thanks to Michael Jackson for guidance and assistance with sorting.

\section{Funding}

No specific funding was awarded for this project. The authors were funded by Breast Cancer Now (PS, HH), CRUK (PS, HP) and the University of Manchester (PS, JT and CB).

\section{Availability of data and materials}

All data generated or analysed during this study are included in this published article (and its Supplementary Information files).

\section{Authors' contributions}

$\mathrm{HH}$ conceived of and performed the majority of the work and wrote the manuscript. PS assisted in project design and writing of manuscript. HP performed data analysis of immunocytochemistry and assisted in manuscript editing. JT and CB performed the $\mathrm{CoCl}_{2}$ experiments. All authors have read and approved the manuscript.

Ethics approval and consent to participate

Not applicable.

\section{Competing interests}

The authors declare that they have no competing interests.

\section{Publisher's Note}

Springer Nature remains neutral with regard to jurisdictional claims in published maps and institutional affiliations.

Received: 5 March 2018 Accepted: 5 June 2018

Published online: 20 June 2018

\section{References}

1. Eccles SA, Aboagye EO, Ali S, Anderson AS, Armes J, Berditchevski F, et al. Critical research gaps and translational priorities for the successful prevention and treatment of breast cancer. Breast Cancer Res. 2013;15(5):R92.

2. Axelson H, Fredlund E, Ovenberger M, Landberg G, Pahlman S. Hypoxiainduced dedifferentiation of tumor cells-a mechanism behind heterogeneity and aggressiveness of solid tumors. Semin Cell Dev Biol. 2005;16(4-5):554-63.

3. Helczynska K, Kronblad A, Jogi A, Nilsson E, Beckman S, Landberg G, et al. Hypoxia promotes a dedifferentiated phenotype in ductal breast carcinoma in situ. Cancer Res. 2003;63(7):1441-4.

4. Bos R, van Diest PJ, van der Groep P, Shvarts A, Greijer AE, van der Wall E. Expression of hypoxia-inducible factor-1alpha and cell cycle proteins in invasive breast cancer are estrogen receptor related. Breast Cancer Res. 2004;6(4):R450-9. 
5. Flamant L, Notte A, Ninane N, Raes M, Michiels C. Anti-apoptotic role of HIF1 and AP-1 in paclitaxel exposed breast cancer cells under hypoxia. Mol Cancer. 2010;9:191.

6. Harrison H, Rogerson L, Gregson HJ, Brennan KR, Clarke RB, Landberg G. Contrasting hypoxic effects on breast cancer stem cell hierarchy is dependent on ER-alpha status. Cancer Res. 2013;73(4):1420-33.

7. Lundgren K, Nordenskjold B, Landberg G. Hypoxia, snail and incomplete epithelial-mesenchymal transition in breast cancer. Br J Cancer. 2009; 101(10):1769-81.

8. Sahlgren C, Gustafsson MV, Jin S, Poellinger L, Lendahl U. Notch signaling mediates hypoxia-induced tumor cell migration and invasion. Proc Natl Acad Sci U S A. 2008;105(17):6392-7.

9. Samanta D, Gilkes DM, Chaturvedi P, Xiang L, Semenza GL. Hypoxia-inducible factors are required for chemotherapy resistance of breast cancer stem cells. Proceedings of the National Academy of Sciences. 2014;111(50):E5429-E38.

10. Raval RR, Lau KW, Tran MG, Sowter HM, Mandriota SJ, Li JL, et al. Contrasting properties of hypoxia-inducible factor 1 (HIF-1) and HIF-2 in von HippelLindau-associated renal cell carcinoma. Mol Cell Biol. 2005;25(13):5675-86.

11. Michiels C. Physiological and pathological responses to hypoxia. Am J Pathol. 2004;164(6):1875-82.

12. Gammon L, Biddle A, Heywood HK, Johannessen AC, Mackenzie IC. Sub-sets of Cancer stem cells differ intrinsically in their patterns of oxygen metabolism. PLoS One. 2013;8(4):e62493.

13. Shaw FL, Harrison H, Spence K, Ablett MP, Simoes BM, Farnie G, et al. A detailed mammosphere assay protocol for the quantification of breast stem cell activity. J Mammary Gland Biol Neoplasia. 2012;17(2):111-7.

14. Schindelin J, Arganda-Carreras I, Frise E, Kaynig V, Longair M, Pietzsch T, et al. Fiji: an open-source platform for biological-image analysis. Nat Meth. 2012;9(7):676-82.

15. Iwamoto M, Bjorklund T, Lundberg C, Kirik D, Wandless TJ. A general chemical method to regulate protein stability in the mammalian central nervous system. Chem Biol. 2010;17(9):981-8.

16. Tai K, Quintino L, Isaksson C, Gussing F, Lundberg C. Destabilizing domains mediate reversible transgene expression in the brain. PLoS One. 2012;7(9): e46269.

17. Yan Q, Bartz S, Mao M, Li L, Kaelin WG Jr. The hypoxia-inducible factor 2alpha N-terminal and C-terminal transactivation domains cooperate to promote renal tumorigenesis in vivo. Mol Cell Biol. 2007;27(6):2092-102.

18. Cox TR, Rumney RMH, Schoof EM, Perryman L, Hoye AM, Agrawal A, et al. The hypoxic cancer secretome induces pre-metastatic bone lesions through lysyl oxidase. Nature. 2015;522(7554):106-10.

19. Hubbi ME, Semenza GL. Regulation of cell proliferation by hypoxia-inducible factors. Am J Physiol Cell Physiol. 2015;309(12):C775-C82.

20. Gunaratnam L, Morley M, Franovic A, de Paulsen N, Mekhail K, Parolin DA, et al. Hypoxia inducible factor activates the transforming growth factor-alpha/ epidermal growth factor receptor growth stimulatory pathway in $\mathrm{VHL}(-/-)$ renal cell carcinoma cells. J Biol Chem. 2003;278(45):44966-74.

21. Auvinen PK, Lipponen PK, Kataja W, Johansson RT, Syrjänen KJ. Prognostic significance of TGF-a expression in breast Cancer. Acta Oncol. 1996;35(8): 995-8.

\section{Ready to submit your research? Choose BMC and benefit from:}

- fast, convenient online submission

- thorough peer review by experienced researchers in your field

- rapid publication on acceptance

- support for research data, including large and complex data types

- gold Open Access which fosters wider collaboration and increased citations

- maximum visibility for your research: over $100 \mathrm{M}$ website views per year

At BMC, research is always in progress.

Learn more biomedcentral.com/submissions 